\title{
Morphological and Properties Characterization of Melt-Spun Poly(lactic acid)/Cellulose Nanowhiskers Fibers: Effect of Filler Content ${ }^{\dagger}$
}

\author{
Tassadit Aouat 1,2 and Mustapha Kaci 1,* \\ 1 Laboratoire des Matériaux Polymères Avancés (LMPA), Université de Bejaia, Bejaia 06000, Algeria; \\ samiatassadit@gmail.com \\ 2 Faculté des Sciences et de la Technologie, Université Yahia Farès, Médéa 26000, Algeria \\ * Correspondence: kacimu@yahoo.fr; Tel.: +213-770-962-592 \\ + Presented at the First International Conference on “Green" Polymer Materials 2020, 5-25 November 2020; \\ Available online: https://cgpm2020.sciforum.net/. \\ Published: date
}

\begin{abstract}
The production of poly(lactic acid) (PLA)/cellulose nanowhiskers (CNW) bionanocomposites represents an efficient route to enlarge their application in many industrial fields, with the possibility to control the properties by filler content adjustment. In this work, fibers yarns of PLA and PLA/CNW filled at 1 and $3 \mathrm{wt} \%$ were prepared by melt spinning in the presence of PLA-grafted-maleic anhydride (PLA-g-MA) used as the compatibilizer. The study aimed at investigating the influence of filler content on the morphology and properties of PLA/CNW bionanocomposites fibers. The results showed that adding only $1 \mathrm{wt} \%$ of CNW in PLA in the presence of compatibilizer improved the morphology and the thermal stability of the bionanocomposite fibers than those filled with $3 \mathrm{wt} \%$, while the tensile properties were almost comparable to the neat PLA.
\end{abstract}

Keywords: Poly(lactic acid); Cellulose nanowhiskers; bionanocomposites; melt spinning; fibers

\section{Introduction}

In recent years, much attention has been paid to biopolymers as an answer to the environmental issues and to the depletion of fossil resources [1]. However, the application of biopolymers is often limited by their poorly mechanical and thermal properties. In order to be competitive to petroleum based polymers, they need to be modified [2]. Nanoscale reinforcements have strong promise in designing ecofriendly green bionanocomposites combining (natural/bio) fibers with biodegradable polymers [3]. In this respect, the attraction for cellulose nanowhiskers (CNW) as reinforcing fillers in the polymer matrices has largely increased due to the unique combination of their impressive mechanical properties coupled with their high aspect ratio. Indeed, CNW offer many advantages such as high reactivity, renewability, biodegradability and natural abundance [4]. Poly(lactic acid) (PLA) is one of the most representative bio-based and biodegradable polymers [5]. However, some of PLA properties, like flexural properties, gas permeability and heat distortion temperature are too low for widespread applications. Therefore, the development of PLA/CNW bionanocomposites could be one of the most efficient routes to improve the properties of the biomaterials by adjusting the suitable filler content. In the field of textiles, the electrospinning process is the most used ones to produce polymer fibers [6]. Nevertheless, the need to develop new processing techniques, as an extension of conventional plastics industry, remains an important challenge. In this paper, melt spinning process was used to elaborate neat PLA and PLA/CNW bionanocomposite fibers at 1 and 3 $w t \%$ in the presence of PLA-grafted-maleic anhydride (PLA-g-MA) used as the compatibilizer at 7 
$w t \%$. Morphology, thermal stability and tensile properties of the fibers were investigated with respect to filler content ratio.

\section{Experiments}

\subsection{Materials}

PLA used was fiber-grade resin 6202D and supplied by Nature Works LLC. According to the manufacturer, the main physical characteristics of the polymer are as follows: $\mathrm{d}=1.24 \mathrm{~g} / \mathrm{cm}^{3}, \mathrm{~T}_{\mathrm{g}}=60$ ${ }^{\circ} \mathrm{C}$ and $\mathrm{T}_{\mathrm{m}} \sim 160-170{ }^{\circ} \mathrm{C}$. Microcrystalline Cellulose (MCC) was supplied by Sigma-Aldrich under the trade name Avicel PH 101 and used as a raw material for extracting cellulose nanowhiskers (CNW) (Aouat et al., 2018). Sulfuric acid 95-97\% from Sigma-Aldrich was used for CNW extraction step. PLA-grafted-maleic anhydride (PLA-g-MA) ( $3 \%$ of MA) used as the compatibilizer for the PLA bionanocomposite fibers, was prepared in the Materia Nova laboratory (Mons, Belgium) by reactive extrusion in a Leistritz twin-screw extruder $(\mathrm{L} / \mathrm{D}=50)$.

\subsection{Preparation of PLA Fiber Yarns by Melt Spinning}

Neat PLA and PLA/CNW bionanocomposite fiber yarns were manufactured in two steps. However prior to processing, both CNW and PLA were dried at $60^{\circ} \mathrm{C}$ for $12 \mathrm{~h}$ to remove the moisture. The first step was the transformation of PLA and PLA bionanocomposites to pellets using a ThermoHaake co-rotating intermeshing twin-screw extruder $(\mathrm{L} / \mathrm{D}=25)$ at 1 and $3 \mathrm{wt} \%$ of $\mathrm{CNW}$. The screw speed was kept at $100 \mathrm{rpm}$, while the temperature profile in the barrel was $160-190{ }^{\circ} \mathrm{C}$. The extruded materials were directly granulated and designed as PLA, PLA/CNW1 and PLA/CNW3. Fiber yarns were elaborated by melt spinning machine, Model Spinboy I, manufactured by Busschaert Engineering. The fiber yarns were covered with an appropriate spin finish (oil/water emulsion composed of a lubricant, an antistatic agent, a cohesion agent and surfactants), which provides the fibers cohesion along the process, rolled up on two heated rolls with varying speeds ( $S_{R 1}$ and $S_{R 2}$ ) in order to ensure the optimal drawing.

\subsection{Characterization Techniques}

\subsubsection{Scanning Electron Microscopy (SEM)}

A QUANTA 200 FEG (FEI Company) Scanning Electron Microscope (SEM) was used to investigate the external as well as the fracture surface morphology of CNW fibers. The fibers surface was coated with a carbon thin layer before SEM observations.

\subsubsection{Tensile Measurements}

Tensile measurements of fibers were performed by a MTS machine following the standard NF EN ISO 2062. The cell force used was $1 \mathrm{KN}$ with a loading speed of $200 \mathrm{~mm} / \mathrm{min}$ and a distance of $200 \mathrm{~mm}$ between grips. All tensile tests were carried out on specimens previously stored for at least $48 \mathrm{~h}$ at $20 \pm 2{ }^{\circ} \mathrm{C}$ under $50 \pm 3 \% \mathrm{RH}$. The values represent an average of five replicates.

\subsubsection{Thermogravimetric Analysis (TGA)}

TGA analysis was performed on a TGA Setsys instrument (Setaram, Caluire-et-Cuire, France). About $10 \mathrm{mg}$ of samples were heated from 30 to $900{ }^{\circ} \mathrm{C}$. The heating rate was set at $10^{\circ} \mathrm{C} / \mathrm{min}$ under the nitrogen atmosphere and the flow rate of $100 \mathrm{~mL} / \mathrm{min}$.

\section{Results}

\subsection{Morphological Analysis of PLA and PLA Bionanocomposite Fibers}

The morphological investigation of neat PLA and PLA bionanocomposite fibers was performed by SEM. In this respect, Figure $1 \mathrm{a}-\mathrm{c}$ shows the external surface of neat PLA and PLA 
bionanocomposite fibers filled at 1 and $3 \mathrm{wt} \%$ of $\mathrm{CNW}$, respectively. Figure $2 \mathrm{a}-\mathrm{c}$ show the morphology in cross sectional area of the corresponding samples. In Figure 1a, the external surface of neat PLA fibers is smooth and regular with a good circular-shape. Moreover, no surface defects are observable on the cross-sectional area of neat PLA fibers as shown in Figure 2a. For the PLA bionanocomposite fibers, the addition of $\mathrm{CNW}$ affects the morphological surface as illustrated in Figure $1 \mathrm{~b}$ and $\mathrm{c}$ in comparison with that of neat PLA (Figure 1a). Further, the effect is more pronounced at $3 \mathrm{wt} \%$. Indeed in Figure $2 \mathrm{~b}$, small filler aggregates are visible on the cross-sectional area of PLA/PLA-g-MA/CNW1 whose size significantly increases at $3 \mathrm{wt} \%$ (Figure 2c) displaying lower fibers yarns regularity and a bulging surface.

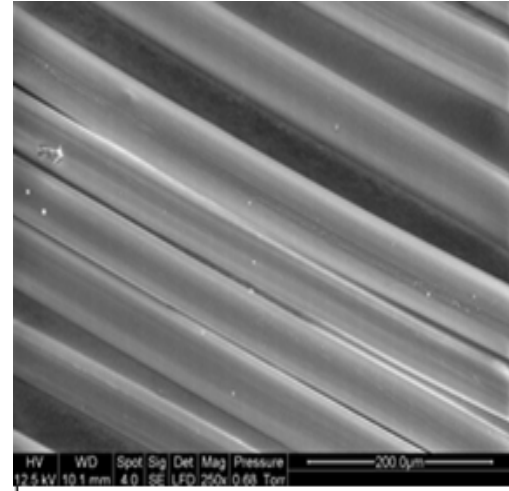

(a)

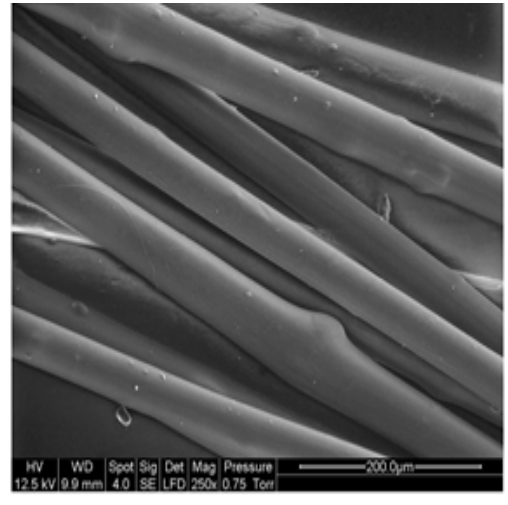

(b)

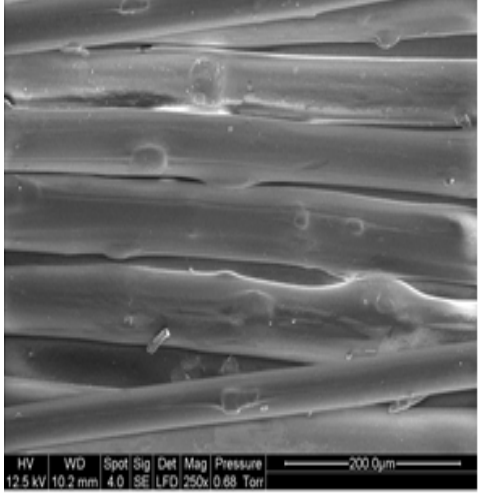

(c)

Figure 1. SEM images of the external surface fibers of: (a) neat PLA and PLA/PLA-g-MA/CNW bionanocomposites (b) $1 \mathrm{wt} \%$ and (c) $3 \mathrm{wt} \%$.

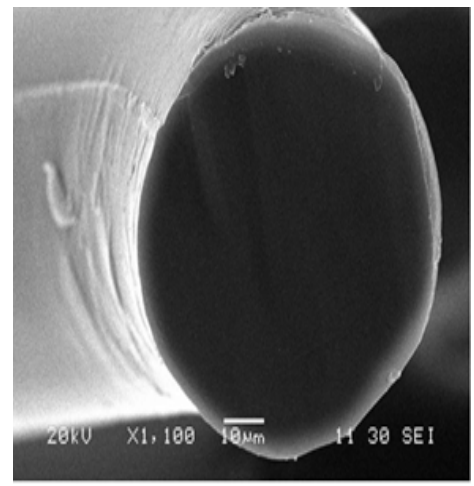

(a)

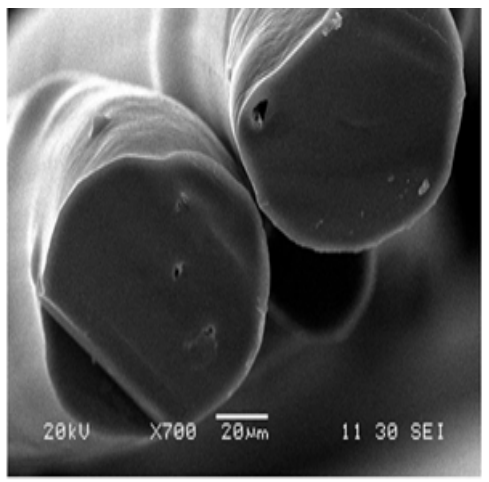

(b)

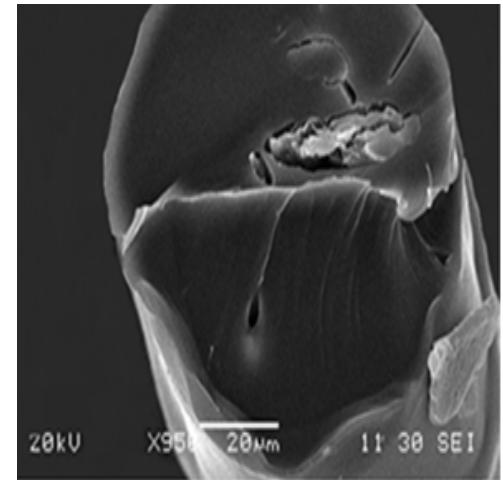

(c)

Figure 2. SEM images of the cross-sectional surface fibers of: (a) neat PLA and PLA/PLA-g-MA/CNW bionanocomposites (b) $1 \mathrm{wt} \%$ and (c) $3 \mathrm{wt} \%$.

\subsection{Tensile Properties}

The tensile properties of neat PLA fibers and those of PLA/CNW bionanocomposites at 1 and 3 $\mathrm{wt} \%$ filler content are provided in Table 1 . For the PLA/PLA-g-MA/CNW1 fibers, the results indicate an increase in elongation at break by almost $18 \%$ compared to that of neat PLA, whereas Young's modulus and tensile strength at break show almost comparable values within the experimental errors. However for PLA/CNW3 fibers, it is observed that the tensile properties are lower than those filled at $1 \mathrm{wt} \%$ and neat PLA due probably to the melt spun process. 
Table 1. Values of Young's modulus, tensile strength at break and (\%) elongation at break of neat PLA and PLA/CNW bionanocomposite fibers.

\begin{tabular}{cccc}
\hline Samples & $\begin{array}{c}\text { Young's Modulus } \\
\mathbf{( M P a )}\end{array}$ & Tensile Strength at Break (MPa) & $\begin{array}{c}\text { Elongation at Break } \\
\mathbf{( \% )}\end{array}$ \\
\hline PLA & $2510 \pm 158$ & $92.2 \pm 5.4$ & $77.7 \pm 7.3$ \\
PLA/PLA-g-MA/CNW1 & $2334 \pm 99$ & $83.9 \pm 3.8$ & $91.6 \pm 4.9$ \\
PLA/PLA-g-MA/CNW3 & $930 \pm 92$ & $22.2 \pm 1.9$ & $19.0 \pm 3.5$ \\
\hline
\end{tabular}

\subsection{Thermal Stability by TGA}

TGA data, i.e., onset degradation temperature (Tonset), temperature at maximum degradation rate (Tmrd) and residue at $500{ }^{\circ} \mathrm{C}$ of neat PLA and PLA/CNW bionanocomposites fibers are provided in Table 2. It is noticed that the addition of CNW to PLA matrix results in an increase in the thermal stability of the bionanocomposite fibers, in particular at filler content of $1 \mathrm{wt} \%$. Indeed Tonset increases by $15^{\circ} \mathrm{C}$ compared to neat PLA. Furthermore, similar trend is also observed with $\mathrm{T}_{\mathrm{mrd}}$ after adding CNW.

Table 2. TGA data of neat PLA and PLA/CNW bionanocomposite fibers.

\begin{tabular}{cccc}
\hline Samples & $\mathrm{T}_{\text {onset }}\left({ }^{\circ} \mathrm{C}\right)$ & $\mathrm{T}_{\operatorname{mrd}}\left({ }^{\circ} \mathrm{C}\right)$ & Char at $500{ }^{\circ} \mathrm{C}(\mathbf{\%})$ \\
\hline PLA & 311 & 362 & 0.6 \\
PLA/PLA-g-MA/CNW1 & 326 & 369 & 0.1 \\
PLA/PLA-g-MA/CNW3 & 320 & 367 & 1.3 \\
\hline
\end{tabular}

\section{Discussion}

From the morphological observations, it is clearly shown that increasing the filler content from 1 to $3 \mathrm{wt} \%$ results in a poor dispersion of the cellulosic fillers in PLA matrix, much more pronounced at $3 \mathrm{wt} \%$, due to the natural tendency of CNW to re-agglomerate and to form strong hydrogen bonds as the water sublimates. In mechaninal properties, adding CNW at $1 \mathrm{wt} \%$ in PLA bionanocomposites results in a slight decrease in Young's modulus and tensile strength at break $(7.01 \%$ and $9.00 \%$, respectively), whereas, the elongation at break increases by $17.89 \%$. At $3 \mathrm{wt} \%$ of filler content, the decrease is much more considerable for all tensile properties. This may result from the fibers arrangements in the suspensions, which are frozen during the hot-pressing stage due to the polymer melt viscosity [7]. This drawback may be prevented by using electrospinning process. Indeed, Zhou et al. [8] reported that the preparation of CNW based PLA fibers by electrospun process produces fibers of better mechanical performances compared to the melt-spun process. Furthermore, the use of solvent in the electrospinning process leads to a better possibility for $\mathrm{CNW}$ to form a percolating network. The mechanical data are consistent with the morphological observations.

Improvement in thermal stability of PLA/CNW bionanocomposites is most likely due on one hand, to the restriction of the mobility of polymer chains and on the other hand, to limit the decomposition as a result of the homogeneous dispersion of $\mathrm{CNW}$ in the polymer matrix, in particular at $1 \mathrm{wt} \%$. of $\mathrm{CNW}$.

\section{Conclusions}

The effect of filler content on the morphology and properties of PLA and PLA/CNW bionanocomposite fibers prepared by melt-spinning process at 1 and $3 \mathrm{wt} \%$ were investigated by several techniques such as SEM, TGA and tensile measurements. It can be concluded that overall, the melt spinning of cellulosic PLA fibers was suitably performed at 1 and $3 \mathrm{wt} \%$. All results indicated clearly that better fibers performances were achieved by adding CNW at $1 \mathrm{wt} \%$ in PLA compared to $3 \mathrm{wt} \%$. Indeed a better morphological surface was observed at $1 \mathrm{wt} \%$ than $3 \mathrm{wt} \%$ in PLA matrix and almost $18 \%$ increase in elongation at break was obtained compared to neat PLA. In addition, the onset degradation temperature was increased by $15^{\circ} \mathrm{C}$ at $1 \mathrm{wt} \%$, which indicates a better thermal stability. Finally, the study showed that $\mathrm{CNW}$ is a promising reinforcement for biodegradable polymers such as PLA. 
Author Contributions: T.A. performed the experiments and contributed reagents/materials/analysis tools and M.K. analyzed the data and wrote the paper.

Acknowledgments: The authors are indebted to the staff of ENSAIT-Roubaix (France) for hosting TA for an internship.

Conflicts of Interest: The authors declare no conflict of interest.

\section{Abbreviations}

The following abbreviations are used in this manuscript:

$\begin{array}{ll}\text { PLA } & \text { poly(lactic acid) } \\ \text { CNW } & \text { cellulose nanowhiskers } \\ \text { PLA-g-MA } & \text { PLA-grafted-maleic anhydrid } \\ \text { MCC } & \text { Microcrystalline Cellulose } \\ \text { SEM } & \text { Scanning Electron Microscopy } \\ \text { TGA } & \text { Thermogravimetric analysis }\end{array}$

\section{References}

1. Dehouche, N.; Kaci, M.; Kaid, N. Thermo-mechanical recycling effects on morphology and properties of ethylene vinyl acetate copolymer/olive husk flour composites. Int. J. Plast. Technol. 2019, 23, 246-252, doi:10.1007/s12588-019-09256-1.

2. De Paula, E.L.; Mano, V.; Pereira, F.V. Influence of cellulose nanowhiskers on the hydrolytic degradation behavior of poly(d,l-lactide). Polym. Degrad. Stab. 2011, 96, 1631-1638, doi:10.1016/j.polymdegradstab.2011.06.006.

3. Valentini, F.; Dorigato, A.; Rigotti, D.; Pegoretti, A. Polyhydroxyalkanoates/Fibrillated Nanocellulose Composites for Additive Manufacturing. J. Polym. Environ. 2019, 27, 1333-1341, doi:10.1007/s10924-01901429-8.

4. Aouat, T.; Kaci, M.; Devaux, E.; Campagne, C.; Cayla, A.; Dumazert, L.; Lopez-Cuesta, J.-M. Morphological, mechanical, and thermal characterization of poly (lactic acid)/cellulose multifilament fibers prepared by melt spinning. Adv. Polym. Technol. 2018, 37, 1193-1205.

5. Nampoothiri, K.M.; Nair, N.R.; John, R.P. An overview of the recent developments in polylactide (PLA) research. Bioresour. Technol. 2010, 101, 8493-8501, doi:10.1016/j.biortech.2010.05.092.

6. Park, W.-I.; Kang, M.; Kim, H.-S.; Jin, H.-J. Electrospinning of Poly(ethylene oxide) with Bacterial Cellulose Whiskers. Macromol. Symp. 2007, 249, 289-294, doi:10.1002/masy.200750347.

7. Peresin, M.S.; Habibi, Y.; Zoppe, J.O.; Pawlak, J.J.; Rojas, O.J. Nanofiber Composites of Polyvinyl Alcohol and Cellulose Nanocrystals: Manufacture and Characterization. Biomacromolecules 2010, 11, 674-681, doi:10.1021/bm901254n.

8. Zhou, C.; Shi, Q.; Guo, W.; Terrell, L.; Qureshi, A.T.; Hayes, D.J.; Wu, Q. Electrospun Bio-Nanocomposite Scaffolds for Bone Tissue Engineering by Cellulose Nanocrystals Reinforcing Maleic Anhydride Grafted PLA. ACS Appl. Mater. Interfaces 2013, 5, 3847-3854, doi:10.1021/am4005072.

Publisher's Note: MDPI stays neutral with regard to jurisdictional claims in published maps and institutional affiliations.

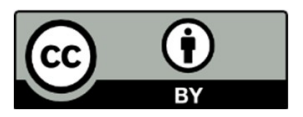

(C) 2020 by the authors. Licensee MDPI, Basel, Switzerland. This article is an open access article distributed under the terms and conditions of the Creative Commons Attribution (CC
(http://creativecommons.org/licenses/by/4.0/). BY) license 